AperTO - Archivio Istituzionale Open Access dell'Università di Torino

\title{
Phytochemical and microbiological stability of spent espresso coffee grounds in capsules
}

\section{This is the author's manuscript}

Original Citation:

Availability:

This version is available http://hdl.handle.net/2318/148274

since 2017-05-18T16:36:46Z

Published version:

DOI:10.1016/j.foodres.2014.02.035

Terms of use:

Open Access

Anyone can freely access the full text of works made available as "Open Access". Works made available under a Creative Commons license can be used according to the terms and conditions of said license. Use of all other works requires consent of the right holder (author or publisher) if not exempted from copyright protection by the applicable law. 


\section{(3) \\ UNIVERSITÀ DEGLI STUDI DI TORINO}

This Accepted Author Manuscript (AAM) is copyrighted and published by Elsevier. It is posted here by agreement between Elsevier and the University of Turin. Changes resulting from the publishing process - such as editing, corrections, structural formatting, and other quality control mechanisms may not be reflected in this version of the text. The definitive version of the text was subsequently published in Phytochemical and microbiological stability of spent espresso coffee grounds in capsules, 61, July 2014, pages 93-99, DOI: 10.1016/j.foodres.2014.02.035.

You may download, copy and otherwise use the AAM for non-commercial purposes provided that your license is limited by the following restrictions:

(1) You may use this AAM for non-commercial purposes only under the terms of the CC-BY-NC-ND license.

(2) The integrity of the work and identification of the author, copyright owner, and publisher must be preserved in any copy.

(3) You must attribute this AAM in the following format: Creative Commons BY-NC-ND license (http://creativecommons.org/licenses/by-nc-nd/4.0/deed.en), +DOI: 10.1016/j.foodres.2014.02.035 


\section{Phytochemical and microbiological stability of spent espresso coffee grounds in capsules}

Simona Belviso $^{\mathrm{a}}$, Daniela Ghirardello ${ }^{\mathrm{a}}$, Kalliopi Rantsiou ${ }^{\mathrm{a}}$, Manuela Giordano $^{\mathrm{a}^{*}}$, Marta Bertolino $^{\mathrm{a}}$,

Denise Borgogna ${ }^{a}$, Maria Chiara Cavallero ${ }^{b}$, Barbara Dal Bello ${ }^{a}$, Clara Cena ${ }^{c}$, Luca Rolle ${ }^{a}$, Giuseppe Zeppa ${ }^{\mathrm{a}}$, Vincenzo Gerbi ${ }^{\mathrm{a}}$

àDipartimento di Scienze Agrarie, Forestali e Alimentari, Università di Torino, via L. da Vinci 44, 10095, Grugliasco (TO), Italy

${ }^{\mathrm{b}}$ Tecnogranda SpA, Via G.B. Conte 19, 12025, Dronero (CN), Italy

${ }^{c}$ Dipartimento di Scienza e Tecnologia del Farmaco, Università di Torino, Via P. Giuria 9, 10125, Torino, Italy

*Corresponding author: via Leonardo da Vinci 44, 10095 Grugliasco (Torino), Italy.

Tel. : +39 0116708817 ; fax : +390116708549

E-mail address: manuela.giordano@unito.it 


\begin{abstract}
Wet spent coffee grounds (SCG) from espresso capsules, a post-consumer organic solid residue produced worldwide, were analysed to determine their chemical and microbiological stability during storage. In particular, the changes in the total phenolic content and antioxidant capacity (based on two free radical scavenging assays and one oxygen radical absorbance assay) were determined on espresso SCG stored in capsules for up to one month at room temperature in a container open to the air. Phenolic compounds were also identified and quantified using high performance liquid chromatography coupled with diode array and mass detectors. Microbiological analysis was performed in parallel on the same stored SCG to determine the total counts and quantify the main microbial groups present during the storage. The total phenolic content, antioxidant capacity and the most important bioactive compounds, such as the total caffeoylquinic acids, were significantly stable during storage for up to one month, while overall microbial stability was observed for up to two weeks of storage. Overall, the recovery of espresso coffee capsules within 15 days could guarantee the maintenance of microbiological stability as well as the content of valuable antioxidant compounds.
\end{abstract}

Keywords: spent coffee grounds; espresso capsules; antioxidant assays; bioactive compounds; microbiological stability; storage. 


\section{Introduction}

The need to reduce waste production as well as to minimise its economic and environmental impacts has prompted researchers to optimise extraction techniques with the goal of obtaining bioactive compounds from plant-derived residues (Wijngaard, Hossain, Rai, \& Brunton, 2012). New and promising studies with the aim to chemically characterise fruit and vegetable byproducts and waste biomass have been performed, highlighting their potential use as valuable source of bioactive components such as polyphenols, dietary fibre (Lozano-Sánchez et al., 2011; O’Shea, Arendt, \& Gallagher, 2012) and other molecules (Pfaltzgraff, De Bruyn, Cooper, Budarin, \& Clark, 2013).

Among food manufacturing sectors, the coffee industry produces high quantities of solid wastes and by-products, which recent studies describe to be rich in phytochemicals and bioactive molecules that have potential in the formulation of functional foods (Esquivel \& Jiménez, 2012; Franca \& Oliveira, 2009; Mussatto, Machado, Martins, \& Teixeira, 2011). Spent coffee grounds (SCG) obtained in large quantities from coffee brewing are one of the most interesting organic post-consumer coffee residues. A total of $50 \%$ of SCG come from the industrial preparation of instant soluble coffee (Esquivel \& Jiménez, 2012) and the remaining 50\% come from the worldwide production of different coffee brews in cafeterias, restaurants and homes. Currently, disposable espresso capsules are among the most popular ways to consume coffee brew and are an interesting and widely method adopted in homes or at offices (Parenti, Guerrini, Masella, Spinelli, Calamai, \& Spugnoli, 2014). Spent coffee grounds have recently been characterized showing high quantities of water-soluble organic bioactive antioxidant compounds, such as caffeine, chlorogenic acids and melanoidins (Bravo et al., 2012; Bravo, Monente, Juániz, Paz De Peña, \& Cid, 2013; Panusa, Zuorro, Lavecchia, Marrosu, \& Petrucci, 2013; Ramalakshmi, Rao, Takano-Ishikawa, \& Goto, 2009; Zuorro, \& Lavecchia, 2012) and inorganic components, such as 
minerals (Cruz et al., 2012). Nevertheless, the studies mentioned above have been carried out on fresh spent coffee grounds analysed after stages of preparation such as drying, defatting and/or freeze-drying to preserve the original organic sample. While SCG produced from soluble coffee production can be immediately treated at the industrial level (Bravo et al. 2012), SCG from capsules can be stored in the place where capsules are consumed. Therefore, because one half of the SCG production originates from the consumption of espresso capsules, it would be interesting to know how storage can affect the composition of the bioactive of polyphenolic compounds present in this solid residue and its potential for industrial reuse.

Therefore the aim of this study was to define the stability of antioxidant activity, polyphenolic compounds, bacteria and fungi present in Arabica spent coffee capsules during storage for up to one month in air at room temperature to reflect real storage conditions at home or in the workplace before the industrial reuse of these residues.

\section{Materials and methods}

\subsection{Chemicals and reagents}

n-Hexane, acetone, ethanol, methanol, formic acid, trans-5-O-caffeoylquinic acid (trans-5-CQA), 2,2-diphenyl-1-picrylhydrazyl (DPPH), 2,2'-azino-bis-(3-ethylbenzothiazolin-6-sulfonic acid) diammonium salt (ABTS), 6-hydroxy-2,5,7,8-tetramethylchroman-2-carboxylic acid (Trolox), 2,2'-azobis(2-amidinopropane) dihydrochloride (AAPH) and 3',6'dihydroxyspiro[isobenzofuran-1[3H],9' $[9 \mathrm{H}]-x$ anthen]-3-one (fluorescein), Folin-Ciocalteu's phenol reagent, sodium nitrite, aluminium chloride, potassium persulphate, hydrochloric acid and sodium hydroxide were purchased from Sigma-Aldrich (Milan, Italy). All chemicals were of reagent- or HPLC grade level. Ultra-pure water was produced with a Milli-Q System (Millipore, 
Milan, Italy). Plate Count Agar (PCA), Malt Extract Agar (MTA) and Ringer's solution were supplied by Oxoid (Milan, Italy).

\subsection{SCG samples preparation and storage}

Commercial aluminium coffee capsules (Lavazza Blue Tierra 2 Intenso, 100\% Arabica) from the same batch (one hundred capsules) were provided by Lavazza S.p.A. (Turin, Italy) and used to produce a typical Italian espresso coffee brew with an automatic espresso machine (Lavazza Blue LB 1000, Lavazza, Italy). In particular, one espresso coffee was obtained from each capsule ( $8 \mathrm{~g}$ of ground coffee), using oligomineral water (electrical conductivity $\left(20{ }^{\circ} \mathrm{C}\right) 69.5 \mu \mathrm{S} / \mathrm{cm}$ ) by stopping the espresso machine to obtain an espresso with a final volume of $20 \mathrm{~mL}$. The extraction parameters for espresso production are as follows: water temperature of approximately $90{ }^{\circ} \mathrm{C}$, water pressure of $9 \mathrm{bar}$, percolation time of $10 \mathrm{~s}$ for $20 \mathrm{~mL}$ of espresso. All used capsules were collected and stored in air at room temperature $\left(22{ }^{\circ} \mathrm{C} \pm 3\right)$ in a polyethylene terephthalate container. Spent capsules had twenty-two small holes (each of $2 \mathrm{~mm}$ diameter) in the aluminium cover. After $0,7,15$ and 28 days of storage, ten capsules were randomly opened, the SCG were collected, mixed and immediately used to perform all chemical and microbiological analyses. Unused ground coffee from capsules were analysed as a reference for chemical analyses. Three replicates were carried out for each analysis and each step of storage.

\subsection{Moisture and $\mathrm{pH}$ determination}

The moisture content was determined using an electronic moisture balance (Eurotherm, Gibertini Elettronica, Milan, Italy) with $5 \mathrm{~g}$ of sample. For the determination of $\mathrm{pH}$, samples of coffee or SCG were mixed with ultrapure water 1:25 (w/v) with continuous shaking (Asal srl, Stirrer 711, 
Cernusco sul Naviglio, Milan, Italy) for $15 \mathrm{~min}$ at room temperature. The $\mathrm{pH}$ of the decanted liquid phase was measured for 5 min using a pH-meter (Micro pH 2002, Crison, Italy).

\subsection{Extraction of phenolic compounds}

Extraction of phenolic compounds was carried as reported by Pinelo, Tress, Pedersen, Arnous and Meyer (2007), in agreement with the recent literature (Panusa et al., 2013). Briefly, two grams of coffee or SCG were added to $20 \mathrm{~mL}$ of a mixture of ethanol/water 60:40 (v/v), shaken on an orbital shaker for $30 \mathrm{~min}$ at a constant oscillation (100 oscillations per min) in the dark and at room temperature and then centrifuged $\left(15 \mathrm{~min}, 4^{\circ} \mathrm{C}, 16800 \mathrm{~g}\right.$ ) (Heraeus Megafuge 11R, Thermo Electron, LED GmbH, Germany). The supernatant was filtered $(0.45 \mu \mathrm{m})$, diluted to $25 \mathrm{~mL}$ with ethanol/water 60:40 (v/v) and immediately analysed. The extractions were performed in triplicate for each sample. Extracts were used for the determination of the total phenolic content, antioxidant capacity, HPLC-photo diode array detector (PDA) and MS/MS analyses.

\subsection{Total Phenolic Content (TPC) assay}

TPC was spectrophotometrically assayed by means of the modified Folin-Ciocalteu method (Singleton \& Rossi, 1965; Singleton, Orthofer \& Lamuela-Raventos, 1999). Briefly, $0.5 \mathrm{~mL}$ of phenolic extract was appropriately diluted and mixed with $2.5 \mathrm{~mL}$ of Folin-Ciocalteu reagent that had been diluted with water 1:10 (v/v). The mixture was incubated at room temperature for $3 \mathrm{~min}$, and $2 \mathrm{~mL}$ of $7.5 \%(\mathrm{w} / \mathrm{v})$ aqueous sodium carbonate solution was added. The mixture was incubated at $45{ }^{\circ} \mathrm{C}$ for $15 \mathrm{~min}$ and finally cooled in a water-ice bath to stop the reaction. The specific absorbance at $765 \mathrm{~nm}$ was immediately measured at room temperature with a UV-visible spectrophotometer (UV-1700 PharmaSpec, Shimadzu, Milan, Italy). A mixture of solvent and reagents was used as blank. The total phenolic content was expressed as mg gallic acid 
equivalents (GAE) per gram of sample on a dry basis, through a calibration curve of gallic acid. The linearity range of the calibration curve was $0-250 \mathrm{mg} / \mathrm{L}\left(\mathrm{r}^{2}=0.998\right)$.

\subsection{In vitro Antioxidant Capacity (AC) assays}

\subsubsection{Trolox Equivalent Antioxidant Capacity (TEAC) assay}

The TEAC values of phenolic extracts were estimated according to the original analytical procedure described by Re et al. (1999), with slight modifications. ABTS radical cation (ABTS ${ }^{\circ+}$ ) was produced by reacting $7 \mathrm{mM}$ ABTS stock solution with $2.45 \mathrm{mM}$ potassium persulphate (final concentration). The mixture was allowed to stand in the dark at room temperature for $12-16 \mathrm{~h}$ before use. Immediately before the analysis, the $\mathrm{ABTS}^{\circ+}$ stock solution was diluted with ethanol to reach an absorbance of $0.70( \pm 0.02)$ at $734 \mathrm{~nm}$, and equilibrated at $30^{\circ} \mathrm{C}$. Sample solutions (or standard) $(30 \mu \mathrm{L})$ were mixed with $\mathrm{ABTS}^{\circ+}$ solution $(3 \mathrm{~mL})$. Absorbance readings were taken at $30{ }^{\circ} \mathrm{C}$ exactly 6 min after the initial mixing. An appropriate solvent blank was obtained by mixing $60 \%$ ethanol $(30 \mu \mathrm{L})$ with $\mathrm{ABTS}^{\circ+}$ solution $(3 \mathrm{~mL})$, while absolute ethanol was used as a control. The $\mathrm{ABTS}^{\circ+}$ scavenging effect (\% Inhibition) was calculated using the equation:

$\%$ Inhibition $=\left[\left(A_{734 b l a n k}-A_{734 \text { sample }}\right) / A_{734 \text { blank }}\right] \times 100$ where $A_{734 b \text { lank }}$ and $A_{734 \text { sample }}$ are the absorbances of $\mathrm{ABTS}^{\circ+}$ solution at $734 \mathrm{~nm}$ before and after sample addition. Results are expressed as $\mu$ mol Trolox equivalent (TE) per gram of sample on a dry basis, by means of a dose-response curve for Trolox $(0-350 \mu \mathrm{M})$.

\subsubsection{DPPH Radical Scavenging Capacity (DPPH RSC) assay}

The DPPH RSCs of the phenolic extracts were measured based on the discolouration of the purple colored methanol solution of the 2,2-diphenyl-1-picrylhydrazyl radical (DPPH*). The spectrophotometric assay was conducted according to the method reported by von Gadow,

Joubert \& Hansmann (1997). Briefly, $75 \mu \mathrm{L}$ of sample extract was added to $3 \mathrm{~mL}$ of $6.1 \times 10^{-5} \mathrm{M}$ 
$\mathrm{DPPH}^{\circ}$ solution in methanol. The decrease in absorbance at $515 \mathrm{~nm}$ was recorded at room temperature condition until stable values $(1 \mathrm{~h})$ using methanol as control and methanol solution of $\mathrm{DPPH}^{\bullet}$ as blank. All operations were performed in the dark or dim light (Sharma \& Bhat, 2009). The inhibition percentage (IP) of the $\mathrm{DPPH}^{\bullet}$ by phenolic extracts was calculated according to the formula

$\mathrm{IP}=\left[\left(A_{0 \min }-A_{60 \mathrm{~min}}\right) / A_{0 \min }\right] \times 100$

where $\mathrm{A}_{0 \min }$ is the absorbance of the blank at $\mathrm{t}=0 \mathrm{~min}$, and $\mathrm{A}_{60 \mathrm{~min}}$ is the absorbance of samples at 60 min. Results were expressed as $\mu$ mol Trolox equivalent (TE) per gram of sample on a dry basis, by means of a dose-response curve for Trolox $(0-350 \mu \mathrm{M})$.

\subsubsection{Oxygen Radical Absorbance Capacity (ORAC) assay}

The ORAC assay was carried out in a PerkinElmer 2030 Multilabel Reader with 96-well black plates. The reaction was carried out with $75 \mathrm{mM}$ potassium phosphate buffer ( $\mathrm{pH} 7.4)$ used as a reagent blank and different Trolox solutions, ranging from 0.25 to $6 \mu \mathrm{M}$, were used as standards (Ou, Hampsch-Woodill, \& Prior, 2001). The sample solutions were prepared by diluting phenolic extracts with phosphate buffer. To start the incubation, aliquots of fluorescein (3',6'dihydroxyspiro[isobenzofuran-1[3H],9'[9H]-xanthen]-3-one) solution (150 $\mu \mathrm{L}$ of a $48 \mathrm{nM}$ solution in potassium phosphate buffer) were dispensed into each well, followed by $20 \mu \mathrm{L}$ of either buffer standard or sample solutions added in duplicate. The plate was covered and incubated in the preheated $\left(37^{\circ} \mathrm{C}\right)$ microplate reader for $10 \mathrm{~min}$, which included shaking for 3 min. At the end $30 \mu \mathrm{L}$ of AAPH solution (133 mM in phosphate buffer) were added and the reaction started when the plate was reinserted into the reader at $37{ }^{\circ} \mathrm{C}$. All fluorescence measurements were expressed relative to the initial reading of the fluorescence signal. Readings were repeated every minute for $35 \mathrm{~min}$ at the emission wavelength of $535 \mathrm{~nm}$ with excitation at 
$485 \mathrm{~nm}$. The net area under the curve (AUC) was calculated by subtracting the AUC of the blank from the AUC of either the standard or the sample. The Trolox equivalent molar concentrations of the samples were calculated using a linear regression equation between the Trolox concentration and the corresponding net AUC. To compare the antioxidant activity of the extracts, it was decided to calculate the relative ORAC values as $\mu$ mol of Trolox equivalents present in $1 \mathrm{~g}$ of extract on a dry basis.

\subsection{HPLC-PDA-MS/MS analysis}

A Thermo-Finnigan SpectraSystem HPLC (Thermo-Finnigan, Waltham, USA), equipped with a P2000 binary gradient pump, a SCM 1000 degasser, an AS 3000 automatic injector and a Finnigan Surveyor PDA Plus detector (PDA) coupled in tandem with a API 3200 QTRAP (Applied Biosystem Sciex, Foster City, CA, USA) with a Turbo V source (Applied Biosystem Sciex) was used. The ChromQuest software (version 5.0) was used for instrument control and UV-data collection and processing, while Analyst software (version 1.6) was used for MS/MS analysis. Separation was achieved on a Luna C18 column $(15$ x 2 mm, $5 \mu \mathrm{m}, 100 \AA$, Phenomenex, Castel Maggiore, Italy) equipped with a SecurityGuard ${ }^{\mathrm{TM}}$ analytical guard cartridge system (Phenomenex). The mobile phase was composed of solvent A (formic acid $0.1 \%$ in ultrapure water) and solvent $\mathrm{B}$ (methanol). The flow rate was set at $0.25 \mathrm{~mL} / \mathrm{min}$ and the injection volume was $10 \mu \mathrm{L}$. The elution program was as follows: A 90\% kept in isocratic for 1 min, A $83 \%$ in $29 \mathrm{~min}$, kept in isocratic for $15 \mathrm{~min}$, A $65 \%$ in $10 \mathrm{~min}$, kept in isocratic for $12 \mathrm{~min}$, A $0 \%$ in $8 \mathrm{~min}$, kept in isocratic for $2 \mathrm{~min}$, A $90 \%$ in $15 \mathrm{~min}$. PDA spectra were recorded in full scan modality over the wavelength $(\lambda)$ range of 220 to $600 \mathrm{~nm}$, and quantification was performed using PDA chromatograms extracted at $325 \mathrm{~nm}$ according to a calibration curve obtained for the trans5-CQA analytical standard and expressed as $\mathrm{mg} / \mathrm{kg}$ dry weight (dw). MS/MS conditions for the 
identification of caffeoylquinic acids (CQAs) analysis were optimised using the trans-5-CQA standard. The ion source was operated in negative ion mode using the following conditions: ion spray voltage $-4500 \mathrm{~V}$; turbo spray temperature $500{ }^{\circ} \mathrm{C}$; curtain gas $2.07 \times 10^{5} \mathrm{~Pa}$; interface heater on; nebuliser gas $2.4 \times 10^{5} \mathrm{~Pa}$; heater gas $10 \times 10^{5} \mathrm{~Pa}$. Nitrogen was used as the nebuliser, heater, curtain and collision gas. Masses were recorded in the range of $\mathrm{m} / \mathrm{z} 100-700 \mathrm{amu}$ using an enhanced mass spectrum (EMS) scan experiment with a declustering potential (DP) of $-20 \mathrm{~V}$ and an entrance potential (EP) of $-10 \mathrm{~V}$. Product ions (MS/MS) were generated according to the information depend acquisition (IDA) mode, with a threshold of $50000 \mathrm{cps}$ and a collision energy (CE) of $-30 \mathrm{eV}$ and were collected in enhanced product ions (EPI) mode.

\subsection{Microbiological analysis}

For each sampling point, $10 \mathrm{~g}$ of unused or spent subsample of coffee ground were mixed with 40 $\mathrm{mL}$ of Ringer's solution (Oxoid, Milan, Italy) for 2 min with a stomacher (Interscience, Turin, Italy). Subsequently, serial decimal dilutions were performed and plated, in triplicate, on Plate Count Agar (PCA, Oxoid, Milan, Italy) for enumeration of the total bacterial count and on Malt Extract Agar (MTA, Oxoid, Milan, Italy) for filamentous fungi and yeasts. PCA plates were incubated for $48 \mathrm{~h}$ at $30{ }^{\circ} \mathrm{C}$ while MTA plates at $30{ }^{\circ} \mathrm{C}$ for $72 \mathrm{~h}$. To enumerate thermoresistant bacteria, the homogenate was subjected to a thermal treatment at $80{ }^{\circ} \mathrm{C}$ for 10 minutes and then

plate count was performed on PCA. Filamentous fungi grown on MTA were identified by sequencing of the D1/D2 region of the gene encoding the 26S rRNA (Kurtzman \& Robnett, 1998), as described by Cocolin, Bisson, and Mills (2000).

\subsection{Statistical and mathematical analysis}


A one-way analysis of variance (ANOVA) using Tukey's test for mean comparison was used to highlight significant differences among SCG samples. All calculations were performed with the STATISTICA for Windows statistical software (Release 7.0; StatSoft Inc., Tulsa, OK, USA). An overall antioxidant potency composite index (APCI) was determined (Seeram et al., 2008). An equal weight was assigned to all assays and an index value of 100 was assigned to the best score for each test, and the corresponding index score was then calculated for each sample as follows: antioxidant index score $=($ sample score $/$ best score $) \times 100$.

The average of the index scores obtained in all tests of a specific extract was defined as its APCI.

\section{Results and discussion}

\subsection{Moisture and pH of samples}

The initial moisture content of SCG was approximately 59\% (Table 1), in agreement with values reported for other wet residues (Cruz et al., 2012; Kondamudi, Mohapatra, \& Misra, 2008; Zuorro \& Lavecchia, 2012). This value remained significantly stable for a week. After one month of storage in capsules, a significant decrease of approximately $17 \%$ was observed.

Roasted coffee presented a $\mathrm{pH}$ of 5.46, similar to that reported in other Arabica roasted coffee (Bicho, Leitão, Ramalho, De Alvarenga, \& Lidon, 2011). After espresso production, fresh SCG exhibited a $\mathrm{pH}$ value higher than coffee, in agreement with Cruz et al. (2012). During storage, a slight significant decrease in $\mathrm{pH}$ values of approximately $8 \%$ was observed after one week of storage. However, this observation is probably not correlated with microbial development.

\subsection{Qualitative analysis of phenolic compounds}

A total of 16 phenolic compounds were found in coffee and SCG samples. A representative PDA chromatogram is displayed in Figure 1. Table 2 displays the retention times $\left(R_{t}\right)$, the UV maxima 
$\left(\lambda_{\max }\right)$, the negative pseudomolecular ions $\left([\mathrm{M}-\mathrm{H}]^{-}\right), \mathrm{MS} / \mathrm{MS}$ and the identification method of the detected compounds. All compounds exhibited $\lambda_{\max }$ between 322 and $327 \mathrm{~nm}$, which are characteristic of CQAs, di-CQAs, caffeoylquinolactones (CQL) and feruloylquinolactones (FQL) (Ramalakshmi et al., 2009). A peak at approximately $6^{\text {th }}$ min had the following characteristics, $\lambda_{\max }=323$ and $[\mathrm{M}-\mathrm{H}]^{-}=353$. Despite the fact that no MS/MS typical of CQAs was detected (probably due to the low peak intensity) the compound can be tentatively identified as a CQA isomer on the basis of the findings of Panusa et al. (2013). In addition, this peak was detected only in the SCG sample at time 0 of storage. Peaks 1,3 and $5\left([\mathrm{M}-\mathrm{H}]^{-}\right.$at $m / z$ 353) were identified as 3-CQA, 4-CQA and 5-CQA by comparison with analytical standards and/or on the basis of data reported in literature, whereas peak 2 was annotated as a CQAs isomer on the basis of data reported in literature (Panusa et al., 2013). CQAs have been reported to be the most abundant compounds in green coffee beans and SCG, with 5-CQA as the major component (Farah \& Donangelo, 2006; Bravo et al., 2012). Peaks 4, 9 and 11 ([M-H] $]^{-}$at $\mathrm{m} / \mathrm{z}$ 367) can be assigned to feruloylquinic acids (FQA) (Panusa et al., 2013). The comparison of MS/MS fragments (obtained in this work from a single chromatographic run by applying IDA experiments) with those obtained in analogous studies also allows us to tentatively annotate peak 4 as 5-FQA (Clifford, Johnston, Knight, \& Kuhnert, 2003; Narvaez-Cuenca, Vincken, Zheng, \& Gruppen, 2013), whereas peaks 6-8 and 10 all have $[\mathrm{M}-\mathrm{H}]^{-}$at $\mathrm{m} / \mathrm{z}$ 335. As reported by Jaiswal, Matei, Ullrich, \& Kuhnert (2011), these isobaric molecules can be assigned both to CQL and caffeoylshikimic acids (CSA). In particular, the assignment of peak 6 to CSA and peaks 7, 8 and 10 to CQL may be possible on the basis of the comparison of their MS/MS fragments with literature data (Jaiswal et al., 2011). Peaks 12-15 ([M-H $]^{-}$at $\mathrm{m} / z$ 349) can be tentatively identified as $\mathrm{FQL}$ or feruloylshikimic acids (Jaiswal et al.). However, the assignment of peaks identification cannot be done in this case due to the lack of a significant numbers of MS/MS fragments, probably due to 
the low peak intensities (data not shown). CQL and FQL also have been previously reported in SCG (Farah \& Donangelo, 2006; Panusa et al., 2013). The only peak (16) with $[\mathrm{M}-\mathrm{H}]^{-}$at $\mathrm{m} / z$ 515 may be attributed to a dicaffeoylquinic acid (di-CQAs) isomer among those previously detected in green coffee beans and SCG (Bravo et al., 2012; Perrone, Farah, Donangelo, de Paulis, \& Martin, 2008). Differently from Bravo et al., in this work only one of the dicaffeoylquinic acid isomers was detected, probably for the different extraction conditions used.

\subsection{Phenolic content, antioxidant capacity and amounts of CQAs in SCG}

The mean values of the total phenolic content (TPC) and the antioxidant capacity (AC) assessed during the storage of SCG samples and on untreated grounds coffee are summarised in Table 1. The total phenolic content of intact roasted coffee was similar to those reported for espresso coffee brew (55 mg of GAE/g of coffee) by Pérez-Martínez, Caemmerer, Paz De Peña, Cid, \& Kroh (2010). Also Brezová, Šlebodová, and Staško (2009) reported values of total phenolics ranging from 41 to $58 \mathrm{mg} \mathrm{GAE} / \mathrm{g}$ of different commercial high quality coffees. As expected, after coffee brewing the amount of total phenolics in fresh SCG decreased by approximately $44.6 \%$ with respect to untreated coffee grounds. Panusa et al. reported a TPC in extracts of SCG recovered from used capsules that was two-fold lower than those observed in our fresh SCG samples. This discrepancy could be due to different blends of coffee (not only the species but also the provenience), the type of roasting and the technological extraction parameters. Antioxidants activities data detected using all assays were equally characterised by a decrease in fresh SCG of greater than $40 \%$ with respect to untreated coffee. Because of the use of various extraction techniques for different SCG (e.g. SCG from filter, espresso, plunger or mocha), it is difficult to compare our AC results with those in the literature. For espresso SCG, which would be assumed to be more similar to SCG capsules, Bravo et al. (2012) reported ABTS and DPPH values of 
131.83 and $74.57 \mu \mathrm{mol} \mathrm{TE} / \mathrm{g} \mathrm{dw}$, respectively, while Páscoa, Magalhães, \& Lopes (2013) assessed an ABTS value of $126 \mu \mathrm{mol} \mathrm{TE} / \mathrm{g} \mathrm{dw}$, which is more similar to our results. ORAC data of SCG extracts are limited in scientific literature (Ramalakshmi et al., 2009), and therefore not comparable with our results, due to the fundamental differences in extraction methods used. The stability of TPC for up to 15 days of storage is noteworthy. Only after 28 days of storage, TPC significantly decreased by approximately 26\%, suggesting a minimal degradation of phytochemical compounds. The same trend was observed in the AC assays, with a slight decline of antioxidant capacity during storage, which was significant only for DPPH RSC results after 28 days of storage. In particular, on SCG stored for one month, a decrease of approximately $30 \%$ of DPPH RSC with respect to fresh SCG, and decreases of approximately $26 \%$ and $14 \%$ for TEAC and ORAC values, respectively, were observed. While DPPH RSC and TEAC values decreased linearly as well as TPC, after a strong decrease from untreated coffee to fresh SCG, ORAC levels were substantially preserved for the first 15 days of storage to finally decreased again on the $28^{\text {th }}$ day. The differences in the responses of TPC, DPPH RSC and TEAC and ORAC could be explained by the different reaction mechanisms and/or different affinities for particular antioxidants of these assays (Stratil, Klejdus, \& Kubáň, 2006). Moreover, foods may interfere by having different magnitudes of effect on different assays (Craft, Kerrihard, Amarowicz, \& Pegg, 2012). It is well known that the Folin-Ciocalteu, ABTS and DPPH assays, based on similar electron-transfer redox reactions, are able to assess not only the phenolic compounds but also the antiradical or antioxidant capacity of non-phenolic compounds, such as Maillard reaction products, including melanoidins formed during roasting (Pérez-Martínez et al., 2010). On the contrary, the ORAC assay is typically a hydrogen transfer-based assay that involves a reaction schema in which antioxidants and substrate compete kinetically for generated peroxyl radicals. For this reason, many authors suggest running multiple antioxidant methods to obtain a better 
estimation of the antioxidant capacity of food extracts (Alvarez-Suarez, Tulipani, Romandini, Vidal, \& Battino, 2009; Prior, Wu, \& Schaich, 2005; Seeram et al., 2008). The APCI values were calculated to give an equal weight to all methods used to quantify the antioxidant capacity of the SCG extracts (Table 3). When all methods were combined into a single index of antioxidant activity, the rank order was related to the storage time. The APCI value decreased by approximately 24 points on the $28^{\text {th }}$ day (one third lower antioxidant potency in comparison to the fresh SCG), demonstrating that after two weeks the antioxidant capacity dropped by only approximately $11 \%$.

The total CQAs content has been calculated as the sum of the contents of 3-CQA, CQA, 5-CQA and 4-CQA. CQAs have been reported to be the most abundant compounds in the green coffee beans and SCG (Farah \& Donangelo, 2006; Bravo et al., 2012). According to the literature (Farah, De Paulis, Trugo \& Martis, 2005), the total CQAs of C. arabica greatly decreased from green coffee to roasted coffee, due to the increasing degree of roasting and roasting time (from 52.87 to $2.09 \mathrm{mg} / \mathrm{g} \mathrm{dw}$ ), with lower values assigned to very dark coffee, which is roasted for a longer time. On the basis of these observations, the value of total CQAs obtained in this work for coffee $(8.29 \pm 0.29 \mathrm{mg} / \mathrm{g} \mathrm{dw})$ (Table 1$)$ was similar to those reported for a dark medium coffee roasted for $8 \mathrm{~min}$. The total CQAs of SCG was found to be about four times lower than that of coffee, ranging from 1.95 to $2.31 \mathrm{mg} / \mathrm{g} \mathrm{dw}$. In particular, no significant differences among the total CQAs of SCG at 0, 7 and 28 days of storage were detected. Instead, a significant increase was observed at the $15^{\text {th }}$ day of storage. Values of the total CQAs found in this work are very similar to those obtained by Panusa et al. (2013) $(2.26 \pm 0.06 \mathrm{mg} / \mathrm{g} \mathrm{dw})$ who used a mixture of ethanol/water $(60: 40 \mathrm{v} / \mathrm{v})$ for the extraction as that was used in this study and differently, but a single step of extraction coupled with a higher temperature $\left(60{ }^{\circ} \mathrm{C}\right)$. Instead, the different 
extraction technique used by Bravo et al. is probably the reason for the higher values of CQAs found in their espresso SCG $(6.16 \mathrm{mg} / \mathrm{g} \mathrm{dw})$.

\subsection{Microbiological aspects of SCG samples}

The results of the microbiological analysis of SCG before storage showed negligible microbial contamination (Table 4). On both PCA and MTA media the microbial count was less than 10 colony forming units (cfu/g). In the subsequent sampling points, a progressive increase in the counts on both PCA and MTA media was observed. More specifically, for the first 15 days of storage, the total bacteria detected were on the order of $10^{2}-10^{3} \mathrm{cfu} / \mathrm{g}$, while at 28 days the count reached was above $10^{6} \mathrm{cfu} / \mathrm{g}$. Similarly, the count on MTA was constant, in the order of $10^{2} \mathrm{cfu} / \mathrm{g}$ up to 15 days of storage, thus a characterisation of moulds during this phase was not considered worthwhile, and it reached a final value of $2.2 \times 10^{6} \mathrm{cfu} / \mathrm{g}$ on the $28^{\text {th }}$ day. No thermoresistant spores were detected by the microbiological analysis performed after the thermal treatment of the spent coffee homogenate. Based on the morphology of the fungal colonies, two main populations could be discriminated. To obtain a definitive identification, two representative isolates of each morphology were isolated in pure culture, and the total DNA was extracted. A fragment of the gene encoding the 26S rRNA was PCR amplified, sequenced and identified using the sequence database (http://www.ncbi.nlm.nih.gov) by BLAST comparison (Altschul, Gish, Miller, Myers, \& Lipman, 1990). The two main populations belonged to the species Penicillium expansum and Penicillium toxicarium. In cumulatively assessing the results, it can be concluded that a satisfactory microbial stability for spent coffee stored under uncontrolled conditions would be expected for up to 15 days. Extension of the storage period is not recommended because extensive microbial growth developed after 15 days. 


\section{Conclusions}

Wet exhausted espresso SCG stored in capsules provided, on the basis of this preliminary data, satisfactory microbiological stability for up to approximately 15 days of storage performed at room temperature in air. Moreover, a generally insignificant degradation of more important bioactive compounds such as CQAs and, consequently, stability of antioxidant capacity was observed during storage. The exploitation of this post-consumer stored coffee residue as a renewable source to recover functionalizing molecules could be important, even after a simple and inexpensive aseptic method of capsule storage (containers sprayed with ethanol and/or air removal).

\section{Acknowledgements}

This study was funded by the project 'Ricerca \& Innovazione per il Miglioramento della Sostenibilità della Filiera Agro-alimentare ECOFOOD' - European Fund for Regional Development F.E.S.R. 2007/2013 - European Union, Italian Economy and Finance Ministry, Piedmont Region (Italy). The authors thank Lavazza S.p.A. for kindly providing the roasted coffee capsule samples.

\section{References}

Altschul, S.F., Gish, W., Miller, W., Myers, E.W., \& Lipman, D.J. (1990). Basic local alignment search tool. Journal of Molecular Biology, 215, 403-410.

Alvarez-Suarez, J.M., Tulipani, S., Romandini, S., Vidal, A., \& Battino, M. (2009). Methodological aspects about determination of phenolic compounds and in vitro evaluation of antioxidant capacity in the honey: a review. Current Analytical Chemistry, 5, 293-302. 
Bicho, N. C., Leitão, A. E., Ramalho, J. C., De Alvarenga, N. B., \& Lidon, F. C. (2011). Identification of nutritional descriptors of roasting intensity in beverages of Arabica and Robusta coffee beans. International Journal of Food Sciences and Nutrition, 62, 865-871.

Bravo, J., Juániz, I., Monente, C., Caemmerer, B., Kroh, L. W., Paz De Peña, M., \& Cid, C. (2012). Evaluation of spent coffee obtained from the most common coffeemakers as a source of hydrophilic bioactive compounds. Journal of Agricultural and Food Chemistry, 60, 12565-12573.

Bravo, J., Monente, C., Juániz, I., Paz De Peña, M., \& Cid, C. (2013). Influence of extraction process on antioxidant capacity of spent coffee. Food Research International, 50, 610-616.

Brezová, V., Šlebodová, A., \& Staško, A. (2009). Coffee as a source of antioxidants: An EPR study. Food Chemistry, 114, 859-868.

Clifford, M.N., Johnston, K. L., Knight, S. \& Kuhnert, N. (2003). Hierarchical scheme for LCMSn identification of chlorogenic acids. Journal of Agricultural and Food Chemistry, 51, 2900-2911.

Cocolin, L., Bisson, L. F., \& Mills, D. A. (2000). Direct profiling of the yeast dynamics in wine fermentations. FEMS Microbiology Letters, 189, 81-87.

Craft, B.D., Kerrihard, A. L., Amarowicz, R., \& Pegg, R.B. (2012). Phenol-based antioxidants and the in vitro methods used for their assessment. Comprehensive Reviews in Food Science and Food Safety, 11, 148-173.

Cruz, R., Cardoso, M. M., Fernandes, L., Oliveira, M., Mendes, E., Baptista, P., Morais, S. \& Casal, S. (2012). Espresso coffee residues: a valuable source of unextracted compounds. Journal of Agricultural and Food Chemistry, 60, 7777-7784.

Esquivel, P., \& Jiménez, V. M. (2012). Functional properties of coffee and coffee by-products. Food Research International, 46, 488-495. 
Farah \& Donangelo, 2006. Phenolic compounds in coffee. Brazilian Journal of Plant Physiology, 18, 23-36.

Farah, A., de Paulis, T., Trugo, L. C., \& Martis, P. R. (2005). Effect of roasting on the formation of chlorogenic acid lactones in coffee. Journal of Agricultural and Food Chemistry, 53,15051513.

Franca, A.S. \& Oliveira, L.S. (2009). Agriculture Issues and Policies Series, Agricultural Wastes. In G.S. Ashworth, \& P. Azevedo (Eds.), Coffee processing solid wastes: current uses and future perspectives (pp. 155-189). New York: Nova Science Publishers Inc.

Gadow, A., Joubert, E., \& Hansmann, C. F. (1997). Comparison of antioxidant activity of aspalathin with that of other plant phenols of Rooibosed tea (Aspalathus linearis), $\alpha$ tocopherol, BHT and BHA. Journal of Agricultural and Food Chemistry, 45, 632-648.

Jaiswal, R., Matei, M.F., Ullrich, F., \& Kuhnert, N. (2011). How to distinguish between cinnamoylshikimate esters and chlorogenic acid lactones by liquid chromatography-tandem mass spectrometry. Journal of Mass Spectrometry, 46, 933-942.

Kondamudi, N., Mohapatra, S.K., \& Misra, M. (2008). Spent coffee grounds as a versatile source of green energy. Journal of Agricultural and Food Chemistry, 56, 11757-11760.

Kurtzman, C.P. \& Robnett, C.J. (1998). Identification and phylogeny of ascomycetous yeasts from analysis of nuclear large subunit (26S) ribosomal DNA partial sequence. Antonie van Leeuwenhoek, 73, 331-371.

Lozano-Sánchez, J., Giambanelli, E., Quirantes-Piné, R., Cerretani, L., Bendini, A., SeguraCarretero, A., \& Fernández-Gutiérrez, A. (2011). Wastes generated during the storage of extra virgin olive oil as a natural source of phenolic compounds. Journal of Agricultural and Food Chemistry, 59, 11491-11500. 
Mussatto, S. I., Machado, E.M.S., Martins, S., \& Teixeira, J. A. (2011). Production, composition, and application of coffee and its industrial residues. Food and Bioprocess Technology, 4, $661-672$.

Narvaez-Cuenca, C.-E., Vincken, J.-P., Zheng, C., \& Gruppen, H. (2013). Diversity of (dihydro) hydroxycinnamic acid conjugates in Colombian potato tubers. Food Chemistry, 139, 10871097.

O’Shea, N., Arendt, E.K., \& Gallagher, E. (2012). Dietary fibre and phytochemical characteristics of fruit and vegetable by-products and their recent applications as novel ingredients in food products. Innovative Food Science and Emerging Technologies, 16,1-10.

Ou, B., Hampsch-Woodill, M., \& Prior, R. L. (2001). Development and validation of an improved oxygen radical absorbance capacity assay using fluorescein as the fluorescent probe. Journal of Agricultural and Food Chemistry, 49, 4619-4626.

Panusa, A., Zuorro, A., Lavecchia, R., Marrosu, G., \& Petrucci, R. (2013). Recovery of natural antioxidants from spent coffee grounds. Journal of Agricultural and Food Chemistry, 61, $4162-4168$.

Parenti, A., Guerrini, L., Masella, P., Spinelli, S., Calamai, L., \& Spugnoli, P. (2014). Comparison of espresso coffee brewing techniques. Journal of Food Engineering, 121, 112117.

Páscoa, R.N.M.J, Magalhães, L.M., \& Lopes, J.A. (2013). FT-NIR spectroscopy as a tool for valorization of spent coffee grounds: Application to assessment of antioxidant properties. Food Research International, 51, 579-586.

Pérez-Martínez, M., Caemmerer, B., Paz De Peña, M. Cid, C., \& Kroh, L.W. (2010). Influence of brewing method and acidity regulators on the antioxidant capacity of coffee brews. Journal of Agricultural and Food Chemistry, 58, 2958-2965. 
Perrone, D., Farah, A., Donangelo, C. M., de Paulis, T., \& Martin, P. R. (2008). Comprehensive analysis of major and minor chlorogenic acids and lactones in economically relevant Brazilian coffee cultivars. Food Chemistry, 106, 859-867.

Pfaltzgraff, L. A., De Bruyn, M., Cooper, E. C., Budarin, V., \& Clark, J. H. (2013). Food waste biomass: a resource for high-value chemicals. Green Chemistry, 15, 307-314.

Pinelo, M., Tress, A. G., Pedersen, M., Arnous, A., \& Meyer, A. S. (2007). Effect of cellulases, solvent type and particle size distribution on the extraction of chlorogenic acid and other phenols from spent coffee grounds. American Journal of Food Technology, 2, 641-651.

Prior, R.L., Wu, X., \& Schaich, K. (2005). Standardized methods for the determination of antioxidant capacity and phenolics in foods and dietary supplements. Journal of Agricultural and Food Chemistry, 53, 4290-4302.

Ramalakshmi, K., Rao, L. J. M., Takano-Ishikawa, Y., \& Goto, M. (2009). Bioactivities of lowgrade green coffee and spent coffee in different in vitro model systems. Food Chemistry, 115, 79-85.

Re, R., Pellegrini, N., Proteggente, A., Pannala, A., Yang, M., \& Rice-Evans, C. (1999). Antioxidant activity applying an improved ABTS radical cation decolourization assay. Free Radical Biology and Medicine, 26, 1231-1237.

Seeram, N. P., Aviram, M., Zhang, Y., Henning, S.M., Feng, L., Dreher, M., \& Heber, D. (2008). Comparison of antioxidant potency of commonly consumed polyphenol-rich beverages in the United States. Journal of Agricultural and Food Chemistry, 56, 1415-1422.

Sharma, O.P., \& Bhat, T.K. (2009). DPPH antioxidant assay revisited. Food Chemistry, 113, $1202-1205$.

Singleton, V.L., \& Rossi, J. A. (1965). Colourimetry of total phenolics with phosphomolybdicphosphotungstic acid reagents. American Journal of Enology and Viticulture, 16, 144-158. 
Singleton, V.L., Orthofer, R., \& Lamuela-Raventós, R.M. (1999). Analysis of total phenols and other oxidation substrates and antioxidants by means of Folin-Ciocaltau reagent. Methods in Enzymology, 299, 152-178.

Stratil, P., Klejdus, B., \& Kubáň, V. (2006). Determination of total content of phenolic compound and their antioxidant activity in vegetables - Evaluation of spectrophometric methods. Journal of Agricultural and Food Chemistry, 54, 607-616.

Wijngaard, H., Hossain, M. B., Rai, D. K., \& Brunton, N. (2012). Techniques to extract bioactive compounds from food by-products of plant origin. Food Research International, 46, 505513.

Zuorro, A., \& Lavecchia, R. (2012). Spent coffee grounds as a valuable source of phenolic compounds and bioenergy. Journal of Cleaner Production, 34, 49-56.

\section{Figure Captions}

Figure 1. Typical HPLC-PDA chromatogram of bioactive compounds of SCG extracted at $\lambda=325$ nm. Peaks 1-16 correspond to, 3- $O$-CQA (1); CQA (2); 5- $O$-CQA (3); FQA (4); 4- $O$-CQA (5); CQL (6); CQL (7); CQL (8); FQA (9); CQL (10); FQA (11); FQL (12); FQL (13); FQL (14); FQL (15); di-CQA (16). 


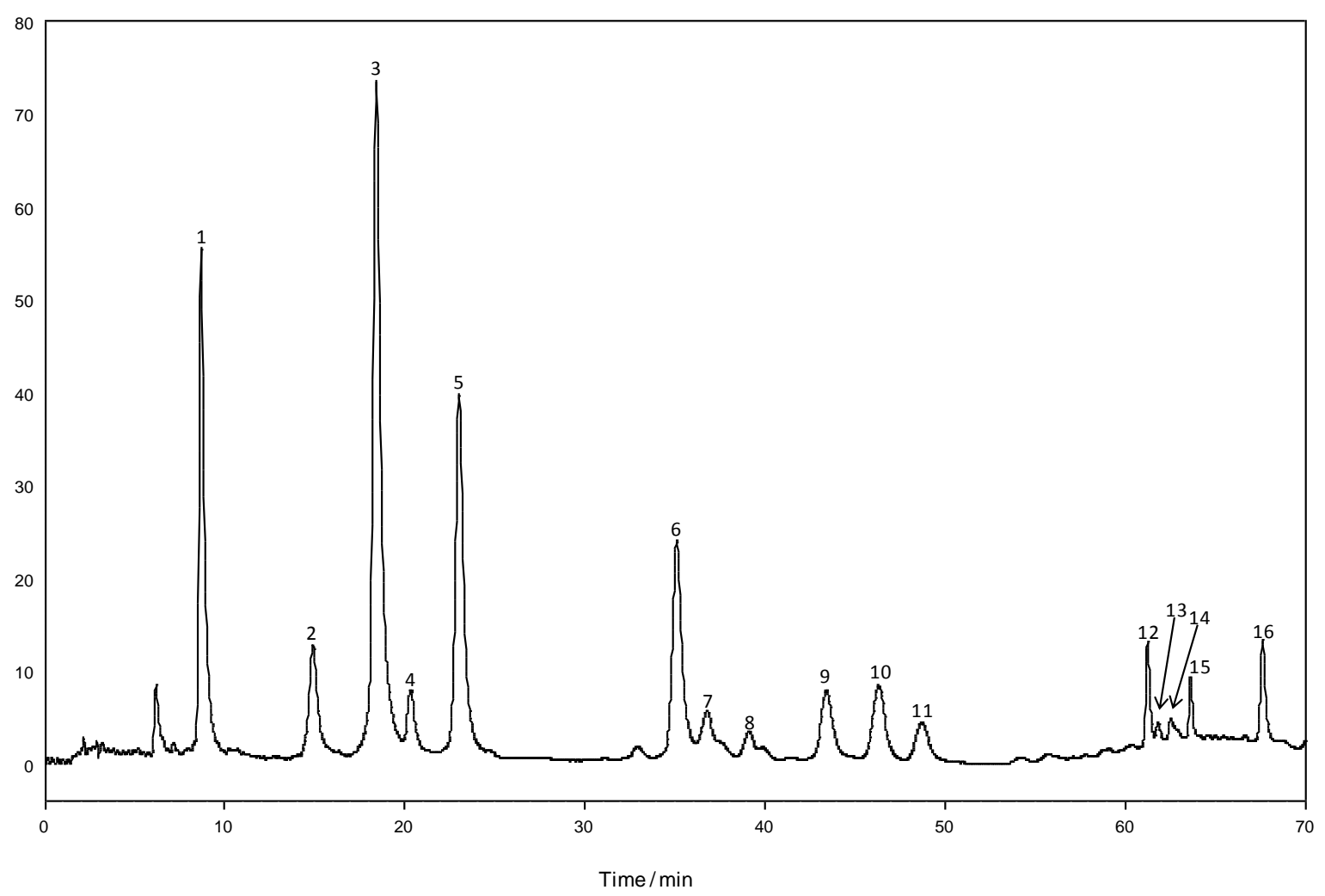

Figure 1. Typical HPLC-PDA chromatogram of bioactive compounds of SCG extracted at $\lambda=325$ nm . Peaks 1-16 correspond to, 3- $O$-CQA (1); CQA (2); 5-O-CQA (3); FQA (4); 4- $O$-CQA (5); CQL (6); CQL (7); CQL (8); FQA (9); CQL (10); FQA (11); FQL (12); FQL (13); FQL (14); FQL (15); di-CQA (16). 
Table 1. Values of $\mathrm{pH}$, moisture, phenolic content (TPC), antioxidant capacity (RSC, TEAC and ORAC) and total caffeoylquinic acids (CQAs) on roasted coffee and spent coffee grounds during storage.

\begin{tabular}{|c|c|c|c|c|c|c|}
\hline & \multirow{3}{*}{ Coffee } & \multicolumn{5}{|c|}{ Spent Coffee Grounds } \\
\hline & & \multicolumn{4}{|c|}{ Storage days } & \multirow[b]{2}{*}{$p$} \\
\hline & & 0 & 7 & 15 & 28 & \\
\hline $\mathrm{pH}$ & $5.46 \pm 0.31$ & $5.92 \pm 0.05^{\mathrm{c}}$ & $5.44 \pm 0.06^{\mathrm{b}}$ & $5.17 \pm 0.05^{\mathrm{a}}$ & $5.24 \pm 0.07^{\mathrm{a}}$ & $* * *$ \\
\hline $\begin{array}{l}\text { Moisture } \\
(\% \mathrm{w} / \mathrm{w})\end{array}$ & $17.6 \pm 0.02$ & $59.08 \pm 0.02^{\mathrm{c}}$ & $57.56 \pm 0.0^{\mathrm{c}}$ & $53.91 \pm 0.0^{\mathrm{b}}$ & $49.17 \pm 0.0^{\mathrm{a}}$ & $* * *$ \\
\hline $\begin{array}{c}\text { TPC } \\
(\mathrm{mg} \mathrm{GAE} / \mathrm{g} \mathrm{dw})\end{array}$ & $45.48 \pm 6.59$ & $25.17 \pm 2.14^{\mathrm{b}}$ & $24.30 \pm 0.07^{\mathrm{b}}$ & $21.89 \pm 2.35^{\mathrm{ab}}$ & $18.60 \pm 1.50^{\mathrm{a}}$ & $* *$ \\
\hline $\begin{array}{c}\text { DPPH RSC } \\
(\mu \mathrm{mol} T E / g \mathrm{dw})\end{array}$ & $227.96 \pm 33.70$ & $132.48 \pm 22.83^{\mathrm{b}}$ & $119.56 \pm 2.21^{\mathrm{ab}}$ & $109.13 \pm 16.23^{\mathrm{ab}}$ & $92.59 \pm 7.10^{\mathrm{a}}$ & $*$ \\
\hline $\begin{array}{c}\text { TEAC } \\
(\mu \mathrm{mol} \mathrm{TE} / \mathrm{g} \mathrm{dw})\end{array}$ & $201.85 \pm 28.64$ & $119.48 \pm 27.54$ & $105.93 \pm 3.64$ & $100.07 \pm 5.38$ & $88.57 \pm 11.00$ & $\mathrm{~ns}$ \\
\hline $\begin{array}{c}\text { ORAC } \\
(\mu \mathrm{mol} \mathrm{TE} / \mathrm{g} \mathrm{dw})\end{array}$ & $889.39 \pm 49.13$ & $477.65 \pm 20.11$ & $487.35 \pm 52.90$ & $483.94 \pm 23.08$ & $411.74 \pm 27.91$ & ns \\
\hline $\begin{array}{l}\text { tot CQAs } \\
(\mathrm{mg} / \mathrm{g} \mathrm{dw})\end{array}$ & $8.29 \pm 0.29$ & $1.95 \pm 0.06^{\mathrm{a}}$ & $1.94 \pm 0.05^{\mathrm{a}}$ & $2.31 \pm 0.17^{\mathrm{b}}$ & $2.01 \pm 0.14^{\mathrm{a}}$ & $*$ \\
\hline
\end{tabular}

Data are expressed as mean \pm SD $(\mathrm{n}=3)$. Values in each row having different lowercase letters are significantly different at $p<0.05$; *: significance at $p<0.05$, **: significance at $p<0.01 ; * * *$ : significance at $p<0.001 ; \mathrm{ns}=$ not significant; dw: dry weight; tot CQAs: total caffeoylquinic acids. 
Table 2. LC-MS/MS characteristics of bioactive compounds detected in negative ion mode in SCG samples.

\begin{tabular}{|c|c|c|c|c|c|c|}
\hline Peak & $\mathrm{R}_{\mathrm{t}}(\min )$ & $\lambda_{\max }(\mathrm{nm})$ & $\begin{array}{c}{[\mathrm{M}-\mathrm{H}]^{-}} \\
(\mathrm{m} / \mathrm{z})\end{array}$ & MS/MS $(m / z)$ & Identification $^{\S}$ & §. Ident \\
\hline 1 & 8.7 & 324 & 353 & $191,135,179$ & 3-O-CQA ${ }^{\mathrm{b}}$ & $\begin{array}{l}\text { :Ident } \\
\text { ificatio }\end{array}$ \\
\hline 2 & 14.9 & 324 & 353 & 191,179 & $\mathrm{CQA}^{\mathrm{b}}$ & $\mathrm{n}$ \\
\hline 3 & 18.4 & 325 & 353 & $191,179,135$ & $5-O-\mathrm{CQA}^{\mathrm{a}}$ & metho \\
\hline 4 & 20.3 & 322 & 367 & 193, 134 & $\mathrm{FQA}^{\mathrm{b}}$ & $\begin{array}{l}\mathrm{a}-\mathrm{i} \\
\text { compa }\end{array}$ \\
\hline 5 & 23 & 325 & 353 & $173,179,191,135$ & $4-O-\mathrm{CQA}^{\mathrm{b}}$ & rison \\
\hline 6 & 35.1 & 326 & 335 & $173,161,135,179$ & $\mathrm{CSA}^{\mathrm{b}}$ & \\
\hline 7 & 36.8 & 324 & 335 & $161,135,133$ & $\mathrm{CQL}^{\mathrm{b}}$ & ce \\
\hline 8 & 39.1 & 324 & 335 & $161,173,135$ & $\mathrm{CQL}^{\mathrm{b}}$ & standa \\
\hline 9 & 43.4 & 324 & 367 & 191,173 & $\mathrm{FQA}^{\mathrm{b}}$ & rds; ${ }^{\circ}:$ \\
\hline 10 & 46.3 & 324 & 335 & 161,135 & $\mathrm{CQL}^{\mathrm{b}}$ & ve \\
\hline 11 & 48.7 & 325 & 367 & 191 & $\mathrm{FQA}^{\mathrm{b}}$ & identif \\
\hline 12 & 61.2 & 326 & 349 & 175 & $\mathrm{FQL}^{\mathrm{b}}$ & \\
\hline 13 & 61.8 & 325 & 349 & - & $\mathrm{FQL}^{\mathrm{b}}$ & literatu \\
\hline 14 & 62.6 & 325 & 349 & - & $\mathrm{FQL}^{\mathrm{b}}$ & \\
\hline 15 & 63.6 & 327 & 349 & - & $\mathrm{FQL}^{\mathrm{b}}$ & CQA: \\
\hline 16 & 67.65 & 326 & 515 & $353,335,173,179,191,135$ & $\mathrm{di}^{-C Q A}{ }^{\mathrm{b}}$ & caffeo \\
\hline
\end{tabular}

c acids; FQA: feruloylquinic acids; CQL: chlorogenic acid lactones; CSA: caffeoylshikimic acids; FQA: feruloylquinic acids; FQL: feruloylquinolactones; di-CQA: dicaffeoylquinic acid; -: not present. 
Table 3. Antioxidant Potency Composite Index (APCI) of spent coffee grounds extracts stored for different days.

\begin{tabular}{cccccc}
\hline Storage days & $\begin{array}{c}\text { TPC } \\
\text { index }^{\mathrm{a}}\end{array}$ & $\begin{array}{c}\text { RSC } \\
\text { index }\end{array}$ & $\begin{array}{c}\text { TEAC } \\
\text { index }\end{array}$ & $\begin{array}{c}\text { ORAC } \\
\text { index }\end{array}$ & APCI $^{\mathrm{b}}$ \\
\hline 0 & 100.0 & 100.0 & 100.0 & 98.0 & 99.5 \\
7 & 96.5 & 90.3 & 88.7 & 100.0 & 93.9 \\
15 & 87.0 & 82.4 & 83.8 & 99.3 & 88.1 \\
28 & 73.9 & 69.9 & 74.1 & 84.5 & 75.6 \\
\hline
\end{tabular}

${ }^{\mathrm{a}}$ Antioxidant index score $=[$ (sample score/best score $\left.) \times 100\right]$

${ }^{\mathrm{b}}$ Average of all four tests for each storage day.

Table 4. Results of microbiological analysis on wet spent coffee grounds in capsules during storage.

\begin{tabular}{lll}
\hline Storage days & Total bacterial count & Yeasts and moulds \\
& $\left(\log _{10} \mathrm{cfu} / \mathrm{g}\right)$ & $\left(\log _{10} \mathrm{cfu} / \mathrm{g}\right)$ \\
\hline 0 & $<1^{\mathrm{a} \S}$ & $<1^{\mathrm{a}}$ \\
7 & $3.73 \pm 0.32^{\mathrm{c}}$ & $2.44 \pm 0.20^{\mathrm{b}}$ \\
15 & $2.70 \pm 0.40^{\mathrm{b}}$ & $2.69 \pm 0.61^{\mathrm{c}}$ \\
28 & $>6^{\mathrm{d}}$ & $6.35 \pm 0.50^{\mathrm{d}}$
\end{tabular}

Values are expressed as means of $\log _{10}$ colony forming units per $\mathrm{g} \pm$ standard deviation.

${ }^{\S}$ Values in each column having different letters are significantly different at $p<0.05$. 